\title{
Simultaneous electrokinetic removal of polycyclic aromatic hydrocarbons and metals from a sediment using mixed enhancing agents
}

\author{
M. T. Ammami • A. Benamar $\cdot$ H. Wang $\cdot$ \\ C. Bailleul · M. Legras $\cdot$ F. Le Derf • \\ F. Portet-Koltalo
}

Received: 4 February 2013/Revised: 6 June 2013/Accepted: 9 October 2013/Published online: 30 October 2013

(C) Islamic Azad University (IAU) 2013

\begin{abstract}
The maintenance of harbor waterways generates large amounts of dredged sediments which are often rich in coexisting organic and inorganic contaminants. Electrokinetic remediation treatments have recently been developed for the simultaneous removal of heavy metals and polycyclic aromatic hydrocarbons (PAHs), using various enhancing agents generally tested sequentially. In this study, different processing fluids were tested, alone or mixed, to improve the decontamination of aged model sediment contaminated with cadmium, lead, chromium, copper, zinc, and five PAHs. Nitric acid (NA) and citric acid (CA) were tested to avoid the formation of an alkaline front into the sediment and favor the metals removal, while an anionic surfactant [sodium dodecyl sulfate (SDS)] and a nonionic surfactant (Tween 20) were tested to solubilize and mobilize PAHs. Processing fluids were circulated under a constant voltage gradient of $1 \mathrm{~V} \mathrm{~cm}^{-1}$ for 10-14 days. NA showed an excellent potential to remove metals (76.8-99.9 \% removal) and PAHs (70.3-89.7 \% removal) in a single run. Besides, the mixture of Tween 20 and $\mathrm{CA}$, more environmental friendly, could be considered as
\end{abstract}

M. T. Ammami · F. Le Derf · F. Portet-Koltalo $(\bowtie)$

UMR 6014 COBRA, Université de Rouen,

55 rue Saint Germain, 27000 Évreux, France

e-mail: florence.koltalo@univ-rouen.fr

M. T. Ammami - A. Benamar · H. Wang

Laboratoire Ondes et Milieux Complexes, UMR CNRS 6294,

Université du Havre, 53 rue de Prony, 76600 Le Havre, France

C. Bailleul · M. Legras

Unité AGRI'TERR, Laboratoire BioSol, Esitpa-Ecole

d'Ingénieurs en Agriculture, 3 rue du Tronquet CS 40118,

76134 Mont-Saint-Aignan Cedex, France a relatively good processing fluid for the simultaneous removal of metals (10.3-90.8\% removal) and PAHs (53.6-61.6\% removal) from the fine-grained sediment, while SDS mixed to CA was not a good candidate for this purpose $(0.1-65 \%$ removal for metals and $34.1-41.0 \%$ removal for PAHs).

Keywords Electrokinetic remediation - Polluted sediments · Metals · Polycyclic aromatic hydrocarbon co-contaminants $\cdot$ Surfactants $\cdot$ Citric acid

\section{Introduction}

The maintenance of harbor waterways, which is absolutely necessary for the development of harbors, maintaining sufficient sailing depth, generates large amounts of dredged sediments. In France, materials dredged annually in the harbors and the channels represent about 50 million $\mathrm{m}^{3}$; of that, 24 million $\mathrm{m}^{3}$ concentrate on most of organic and inorganic contaminants (Benamar and Baraud 2011). Dredged materials are no more systematically dumped at sea, to protect aquatic life from the potential toxic effects of sediment-bound contaminants. French guidelines (Geode regulations), dated on June 14, 2000, were adopted within the framework of the OSPAR convention and specify two guidance levels $\left(\mathrm{N}_{1}\right.$ and $\mathrm{N}_{2}$ ) for the chemical contents. They have been established to facilitate the management of dredged sediments. When the concentration of many classes of contaminants is higher than a determined threshold $\left(\mathrm{N}_{2}\right.$ level), dredged sediments must be kept on chosen disposal sites to minimize their adverse impacts on the aquatic environment (Alzieu 2005). Lots of these disposal sites are nearing capacity or are already full. As a 
consequence, reuse solutions, such as in civil engineering, can be proposed, but they generally require previous pretreatments (such as dehydration) and pollution remediation to reduce the amount of contaminants.

Sediment contamination involves different organic, inorganic, and organometallic pollutants, but metals and persistent organic pollutants (such as polycyclic aromatic hydrocarbons PAHs) are particularly of great concern. Indeed, they can accumulate in food chains and may cause higher mortality, reduce growth, or disturb reproductive processes in marine organisms, depending on their level of contamination. The presence of PAHs in the environment is mainly due to the waste discharged from industrialized and urbanized areas, coal tar pavement, off-shore petroleum hydrocarbon production, or petroleum transportation (Froehner et al. 2012a). Because of these recalcitrant contaminants, powerful techniques must be developed to remove them from sediments. They include thermal desorption, washing, bioremediation by aerobic or anaerobic biodegradation, and ultrasonic degradation (Gan et al. 2009; Bremner et al. 2011; Baboshin and Golovleva 2012; Zhang et al. 2012). The properties of sediments differ markedly from soils, because of their higher content of water, clay, silt, and organic matter [this latter fraction having a high capacity to retain PAHs (Froehner et al. 2012b)]. So, technologies which are effective for soils can be impractical for sediments (Mulligan et al. 2001).

Electrokinetic (EK) remediation is accepted as one of the most suitable technologies for extracting metals from fine-grained sediments of low permeability (Kim et al. 2011). Moreover, EK remediation is flexible and can be used as an in situ or ex-situ remediation system (Reddy 2010). Basically, an electric field is applied to the sediment via electrodes, causing movement of charged species in the sediment (by electromigration) to a cathode or to an anode. This electric field is also responsible for the movement of water by electroosmosis, usually towards the cathode, and uncharged contaminants can also be transported with water (Vyrkutyte et al. 2002). But since electromigration has generally a higher impact than electroosmosis, EK remediation focuses on charged ions such as metals (Suer et al. 2003). Successful laboratoryscale electroremediation tests have been reported for sediments, sludge or soils contaminated by metals or metalloids (Yuan and Weng 2006; Al-Hamdan and Reddy 2008; Yuan and Chiang 2008; Gan et al. 2009). However, attention has also focused on removing neutral contaminants by the electroosmotic flow driving force. Although EK process does not seem to be the most adapted technology to remove insoluble hydrophobic pollutants such as PAHs, recent studies demonstrated the treatment's effectiveness (Giannis et al. 2009; Pazos et al. 2010).
However, PAHs removal was mainly investigated from spiked kaolin and from soils (Reddy et al. 2006; Park et al. 2007; Alcantara et al. 2010; Reddy et al. 2010) and only few studies dealt with fine-grained sediments (Genc et al. 2009; Colacicco et al. 2010). Moreover, a major factor complicating the EK remediation is the co-occurrence of organic compounds and metals, because enhancing additives which are necessary to obtain effective removals of each kind of contaminants are not of the same nature (acids or chelatants for metals $v s$ bases, cosolvents or surfactants for PAHs). Studies dealing with the simultaneous electrokinetic removal of metals and PAHs from sediments are not numerous, and further research is needed to improve the understanding of many important factors acting on the process. In particular, physical and chemical effects when using mixtures of flushing reagents remain complex and only few phenomenological studies are reported in literature. Besides, the different enhancing agents such as acids, chelatants or surfactants were generally tested sequentially and not simultaneously during the same run test (Reddy et al. 2009).

In this work, EK remediation at laboratory scale was used to remove five metals $(\mathrm{Cd}, \mathrm{Cr}, \mathrm{Cu}, \mathrm{Zn}$ and $\mathrm{Pb})$ and five PAHs (phenanthrene, fluoranthene, pyrene, chrysene and benzo $[b]$ fluoranthene) from a model sediment mimicking the properties of a natural dredged harbor sediment (the real sediment is located in Normandy, France and was obtained in 2010). This model sediment was more complex than pure kaolinite or sand and was let several months in contact with spiked PAHs. Indeed, we took into consideration the fact that the electrokinetic method, immediately applied on a freshly spiked soil, does not give the same results than on aged spiked soils and obviously than on natural soils, since contaminants are more strongly sorbed on mineral and organic fractions in these two latter cases. Many batch tests were conducted using different types of enhancing agents: strong and weak acids were tested to enhance metals removal whereas solubilizing agents such as anionic and neutral surfactants were tested for removal of PAHs. Mixtures of many of these additives were also tested for the first time, in combination and not sequentially, in order to remove simultaneously metals and PAHs in a single run. Moreover, it was discussed about the opportunity to introduce these mixtures of enhancing agents into the two electrode cells while additives are generally introduced as catholytes (Gidarakos and Giannis 2006) or anolytes (Maturi et al. 2009).

Thus, this paper describes bench scale electrokinetic experiments in order to assess the simultaneous removal of metals and PAHs from a spiked aged model sediment, in only one stage, using combinations of additives which have never been tested together. 


\section{Materials and methods}

Materials

\section{Model sediment}

A model sediment was made up of a mixture of kaolinite (IMERYS, Poigny, France), silt (collected from surface formations covering the chalk plateau in Haute-Normandie, France) and sand (SIKA, Hostun, France) to mimic a dredged sediment from a disposal site managed by a French harbor authority (Table 1). Mineralogy of the model sediment (but also the content of organic matter) was close to the one of the natural sediment. Organic matter (OM), obtained from the decomposition of a vegetable material, was graciously provided by VEOLIA (France). This OM was dried for $48 \mathrm{~h}$ at $50{ }^{\circ} \mathrm{C}$, crushed and sieved through apertures of $355 \mu \mathrm{m}$.

\section{Solvents and contaminants}

Acetonitrile, methylene chloride, toluene, acetone, all of HPLC grade, were obtained from Fisher Scientific France (Illkirsh, France). Nitric acid (65\%) and hydrochloric acid (37\%) were obtained from Panreac (Barcelona, Spain). Sodium chloride (purity 99.5\%), sodium dodecyl sulfate SDS (>99\%), citric acid monohydrate (>98\%) and Tween $20(>97 \%)$ were also purchased from Fisher Scientific. Water was purified and deionized using a direct Q3 system from Millipore (Molsheim, France).

A mixture of five PAHs (Table 1), all obtained from Sigma-Aldrich (St Quentin Fallavier, France), was prepared in acetone (each at $2,000 \mathrm{mg} \mathrm{L}^{-1}$ ). $25 \mathrm{~mL}$ of this mixture was introduced into $500 \mathrm{mg}$ of the inorganic fraction of the model sediment (autoclaved $2 \mathrm{~h}$ at $110{ }^{\circ} \mathrm{C}$ ), to obtain a total PAH contamination of $500 \mathrm{mg} \mathrm{kg}^{-1}$. This sterilized model sediment was shaken under an extractor fan during 2 days to evaporate acetone and then was mixed with $4.38 \mathrm{~kg}$ of sterilized, not contaminated, model sediment. After that, $0.112 \mathrm{~g}$ of organic matter was added and the dry mixture was aged in the dark for 3-6 months, in order to allow strong interactions between PAHs and organic matter to occur. Consequently, we obtained a model sediment with a total PAH contamination of approximately $50 \mathrm{mg} \mathrm{kg}^{-1}$, which is ten times the total PAH level measured in the natural dredged sediment of the Norman disposal site. Contamination of the model sediment by PAHs was above the $\mathrm{N}_{2}$ level (Geode regulations) which raises problems for dredged sediments.

A mixture of five metals was prepared to be introduced in the model sediment containing PAHs (Table 1). Metals were introduced at the $\mathrm{N}_{2}$ level (above which submersion of sediments is subject to strict conditions), except for $\mathrm{Cd}$ which was introduced at ten times its $\mathrm{N}_{2}$ level. Cadmium nitrate tetrahydrate (purity $99.9 \%$ ), chromium nitrate (99\%), copper sulfate (98\%), zinc nitrate hydrate $(99.9 \%)$ and lead nitrate $(99.9 \%)$ were purchased from Sigma-Aldrich France. They were diluted in $180 \mathrm{~mL}$ of deionized water respectively at $0.130,2.770,0.452,3.197$ and $0.639 \mathrm{~g} \mathrm{~L}^{-1}$, and then they were mixed with $360 \mathrm{~g}$ of the dry model sediment contaminated by PAHs. Thus the aqueous phase introduced corresponded to $50 \%$ moisture content (w/w). This mixture was shaken for 3 days after its introduction inside the electrokinetic cell.

\section{Electrokinetic tests}

\section{Electrokinetic setup}

The setup consisted of a sediment chamber made of Teflon PTFE which was $4.9 \mathrm{~cm}$ inside diameter and $14.2 \mathrm{~cm}$

Table 1 Properties of the studied aged model sediment and its spiked contaminants

\begin{tabular}{|c|c|c|c|c|c|c|}
\hline \multicolumn{4}{|l|}{ Model sediment } & \multicolumn{3}{|c|}{ Spiked contaminants } \\
\hline \multirow[t]{3}{*}{ Particle size distribution and diameters } & Clay & $20 \%$ & $\begin{array}{l}d_{\mathrm{p}}<80 \mu \mathrm{m} \\
54 \%<2 \mu \mathrm{m}\end{array}$ & Metals & $\mathrm{Cd}_{\text {II }}$ & $24 \mathrm{mg} \mathrm{kg}^{-1}$ \\
\hline & Silt & $75 \%$ & $d_{\mathrm{p}}=4-100 \mu \mathrm{m}$ & & $\mathrm{Cr}_{\text {III }}$ & $180 \mathrm{mg} \mathrm{kg}^{-1}$ \\
\hline & Sand & $5 \%$ & $d_{\mathrm{p}}=125-315 \mu \mathrm{m}$ & & $\mathrm{Cu}_{\text {II }}$ & $90 \mathrm{mg} \mathrm{kg}^{-1}$ \\
\hline Organic matter content & $2.5 \%$ & & & & $\mathrm{Zn}_{\text {II }}$ & $552 \mathrm{mg} \mathrm{kg}^{-1}$ \\
\hline $\mathrm{pH}$ & 6.8 & & & & $\mathrm{~Pb}_{\text {II }}$ & $200 \mathrm{mg} \mathrm{kg}^{-1}$ \\
\hline Electrical conductivity & $\begin{array}{l}932 \mu \\
4,580\end{array}$ & $\begin{array}{l}{ }^{1} \text { in de } \\
1^{-1} \text { in } s\end{array}$ & $\begin{array}{l}\text { water } \\
\text { ter }\left(20 \mathrm{~g} \mathrm{~L}^{-1} \mathrm{NaCl}\right)\end{array}$ & PAHs & PHEN & $8.6 \pm 0.4 \mathrm{mg} \mathrm{kg}^{-1 \mathrm{a}}$ \\
\hline Moisture content $(\% \mathrm{w} / \mathrm{w})$ & $50 \%$ & & & & $\begin{array}{l}\text { FLT } \\
\text { PYR } \\
\text { CHRYS } \\
\text { B(b)FLT }\end{array}$ & $\begin{array}{l}9.7 \pm 0.4 \mathrm{mg} \mathrm{kg}^{-1 \mathrm{a}} \\
8.6 \pm 0.4 \mathrm{mg} \mathrm{kg}^{-1 \mathrm{a}} \\
10.9 \pm 0.6 \mathrm{mg} \mathrm{kg}^{-1 \mathrm{a}} \\
10.7 \pm 0.8 \mathrm{mg} \mathrm{kg}^{-1 \mathrm{a}}\end{array}$ \\
\hline
\end{tabular}

\footnotetext{
${ }^{a}$ Mean values obtained from 4 replicates after MAE extraction and GC-MS analysis
} 
length (Fig. 1). The two electrode compartments were also made of Teflon ( $4.9 \mathrm{~cm}$ diameter, $5 \mathrm{~cm}$ length) and were separated from the cell containing the sediment by a porous $(0.45 \mu \mathrm{m})$ fiber glass filter paper (Millipore) and a Teflon perforated grid. Two graphite electrode plates were placed in each compartment through a perforated hole. Two peristaltic pumps (KNF Stepdos, Germany) allowed filling each electrode compartment with anolyte and catholyte aqueous solutions, with a low flow rate $\left(10 \mathrm{~mL} \mathrm{~h}^{-1}\right)$. Two glass flasks collected the anodic and cathodic effluents, whose masses were measured periodically: it allowed calculating the electroosmotic flow (EOF) from the difference between the volume generated by the imposed flow and the effluent volume. Three sampling ports were included at approximately $5 \mathrm{~cm}$ intervals in the horizontal direction of the sediment chamber, in order to measure the $\mathrm{pH}$ and the electrical potential variations during the tests.

\section{Testing procedures}

For each test, approximately $540 \mathrm{~g}$ of the wet contaminated model sediment was fully packed into the sediment chamber. The cathode and the anode reservoirs were filled with an aqueous solution containing the same enhancing agents. A constant voltage gradient $\left(1 \mathrm{~V} \mathrm{~cm}^{-1}\right)$ was then applied for 7-14 days, and electrical current was periodically measured during runs. Every $24 \mathrm{~h}$, cathodic and anodic effluents were collected and PAHs and metals concentrations were measured (see "Chemical analysis" section). At the end of a selected time-period, the model sediment was extracted from the apparatus and was cut into 4 equal sections. Then, the residual metals and PAHs could be extracted and analyzed to obtain concentration profiles from the anode to the cathode. A summary of all the run test conditions applied is reported in Table 2.

Sediment $\mathrm{pH}$ and electrical conductivity were measured, respectively, using a M220 $\mathrm{pH}$ meter from Meters Lab Instruments (that was calibrated using standardized $\mathrm{pH}$ solutions) and a HI8733 conductivimeter from Hanna Instruments. In each case, measurements were performed by suspending $1 \mathrm{~g}$ of model sediment in $5 \mathrm{~mL}$ deionized water, after $60 \mathrm{~min}$ of agitation (at $20^{\circ} \mathrm{C}$ ) and filtration.

\section{Chemical analysis}

\section{PAHs analysis}

PAHs remaining in the four sliced sections of the model sediment after electrokinetic treatment were analyzed by gas chromatography coupled to mass spectrometry (GC-MS). Three aliquots of $5 \mathrm{~g}$ of sediment were taken from each section and were dried one night at $35^{\circ} \mathrm{C}$. After crushing, they were extracted by microwave-assisted extraction (MAE) (MARS X, CEM Corporation, Matthews, USA). Each aliquot was mixed with $40 \mathrm{~mL}$ of toluene/acetone $50 / 50(\mathrm{v} / \mathrm{v})$ and then heated at $140{ }^{\circ} \mathrm{C}$ during $30 \mathrm{~min}$, with a power of $1,200 \mathrm{~W}$. Then the extracting solvent was filtered with a Phenex Teflon PTFE filter $(0.45 \mu \mathrm{m})$ (Phenomenex, Le Pecq, France) before GC-MS analysis. After the addition of $10 \mu \mathrm{L}$ of deuterated phenanthrene as an internal standard (100 $\mathrm{mg} \mathrm{L}^{-1}$ ) to $990 \mu \mathrm{L}$ of each liquid extract, $1 \mu \mathrm{L}$ was injected (splitless injection at $280{ }^{\circ} \mathrm{C}$ ) into the gas chromatographer (model 6850 from Agilent, Santa Clara, USA). The MS detector (model 5975C from Agilent) operated at $70 \mathrm{eV}$ with an electron voltage of $1,600 \mathrm{~V}$ in positive ion mode (temperature of the transfer line: $300{ }^{\circ} \mathrm{C}$ ). Separation was performed using a $30 \mathrm{~m} \times 0.25 \mathrm{~mm}$ i.d. capillary column $(0.25 \mu \mathrm{m}$ film thickness $)$, with helium as a carrier gas $\left(1.2 \mathrm{~mL} \mathrm{~min}^{-1}\right)$. Oven temperature was programmed at $55^{\circ} \mathrm{C}$ for $1.2 \mathrm{~min}$, increased to $180{ }^{\circ} \mathrm{C}\left(\right.$ at $40{ }^{\circ} \mathrm{C} \mathrm{min}{ }^{-1}$ ) and then to $300{ }^{\circ} \mathrm{C}$ at $4{ }^{\circ} \mathrm{C} \mathrm{min}^{-1}$. Quantification was based on selected ion monitoring for better sensitivity.

PAHs were also quantified in the aqueous cathodic and anodic effluents by liquid chromatography (HPLC) (126 model pumps from Beckman Coulter, Fullerton, USA) coupled to a fluorimetric (FLD) detector (Prostar 363 from

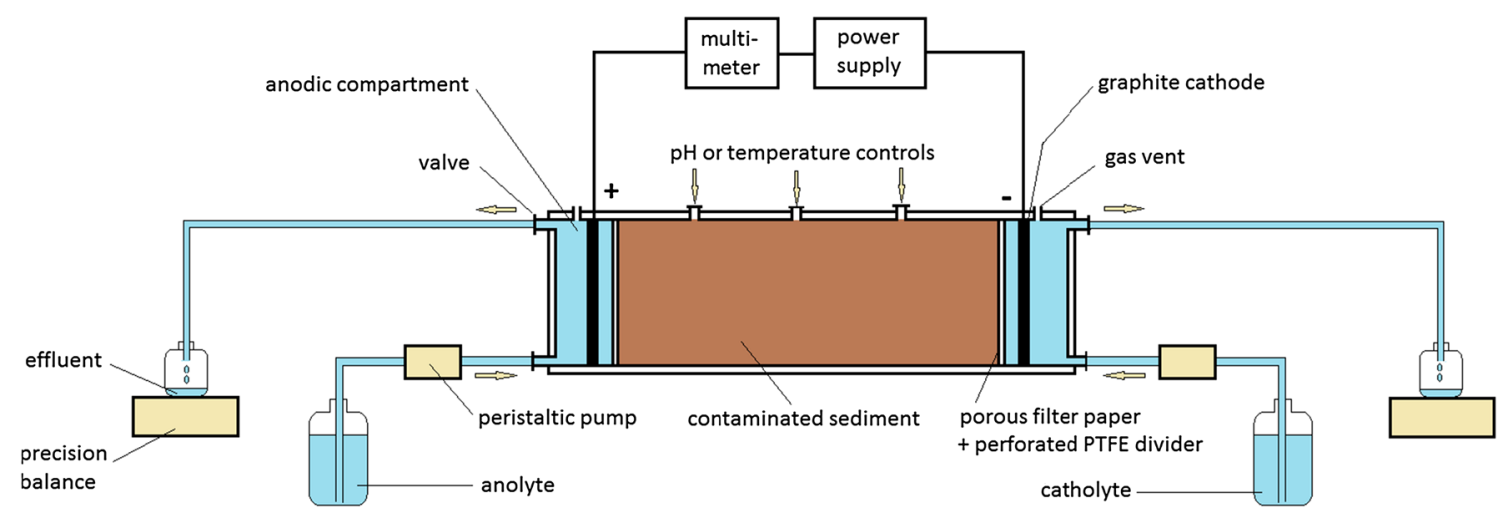

Fig. 1 Schematic of the electrokinetic test apparatus 
Table 2 Conditions for the electrokinetic remediation experiments and metals and PAHs removal efficiencies (\%)

\begin{tabular}{|c|c|c|c|c|c|c|c|c|c|c|c|c|}
\hline \multirow[t]{2}{*}{ Run } & \multirow[t]{2}{*}{ Anolytes and catolytes } & \multirow{2}{*}{$\begin{array}{l}\text { Duration } \\
\text { (days) }\end{array}$} & \multicolumn{5}{|c|}{ Metal removals } & \multicolumn{5}{|c|}{ PAH removals } \\
\hline & & & $\begin{array}{l}\mathrm{Cu} \\
(\%)\end{array}$ & $\begin{array}{l}\mathrm{Cd} \\
(\%)\end{array}$ & $\begin{array}{l}\mathrm{Cr} \\
(\%)\end{array}$ & $\begin{array}{l}\mathrm{Pb} \\
(\%)\end{array}$ & $\begin{array}{l}\mathrm{Zn} \\
(\%)\end{array}$ & $\begin{array}{l}\text { PHEN } \\
(\%)\end{array}$ & $\begin{array}{l}\text { FLT } \\
(\%)\end{array}$ & $\begin{array}{l}\text { PYR } \\
(\%)\end{array}$ & $\begin{array}{l}\text { CHRYS } \\
(\%)\end{array}$ & $\begin{array}{l}\text { B(b)FLT } \\
(\%)\end{array}$ \\
\hline EK1 & Deionized water & 7 & 6.8 & 0.1 & 12.2 & 2.4 & 44.2 & 36.4 & 33.6 & 39.3 & 35.4 & 43.5 \\
\hline EK2 & $\mathrm{NaCl}\left(20 \mathrm{~g} \mathrm{~L}^{-1}\right)$ & 7 & 46.3 & 26 & 39.3 & 58.4 & 43 & 35.2 & 24.4 & 38.6 & 28.0 & 33.8 \\
\hline EK3 & Nitric acid $\left(0.1 \mathrm{~mol} \mathrm{~L}^{-1}\right)$ & 15 & 85.2 & 99.9 & 76.8 & 93.5 & 98.9 & 75.3 & 70.3 & 89.7 & 85.7 & 74.2 \\
\hline EK4 & Citric acid $\left(0.1 \mathrm{~mol} \mathrm{~L}^{-1}\right)$ & 10 & 61.9 & 95.2 & 43.9 & 64.2 & 96.0 & 36.5 & 31.5 & 33.2 & 30.6 & 39.9 \\
\hline EK5 & SDS $\left(0.04 \mathrm{~mol} \mathrm{~L}^{-1}\right)$ & 10 & 45.3 & 32.7 & 23.7 & 50.2 & 87.0 & 29.3 & 20.5 & 26.2 & 22.3 & 26.8 \\
\hline EK6 & Tween $20\left(0.004 \mathrm{~mol} \mathrm{~L}^{-1}\right)$ & 10 & 25.3 & 5.2 & 1.3 & 6.4 & 38.5 & 54.6 & 54.9 & 59.2 & 55.6 & 54.0 \\
\hline EK7 & $\begin{array}{l}\text { Citric acid }\left(0.1 \mathrm{~mol} \mathrm{~L}^{-1}\right) \\
\quad+\operatorname{SDS}\left(0.04 \mathrm{~mol} \mathrm{~L}^{-1}\right)\end{array}$ & 10 & 11.0 & 34.2 & 24.0 & 0.1 & 65.0 & 38.9 & 34.1 & 38.6 & 36.8 & 41.0 \\
\hline EK8 & $\begin{array}{l}\text { Tween } 20\left(0.004 \mathrm{~mol} \mathrm{~L}^{-1}\right) \\
\quad+\text { Citric acid }\left(0.1 \mathrm{~mol} \mathrm{~L}^{-1}\right)\end{array}$ & 10 & 49.2 & 88.0 & 10.3 & 28.5 & 90.8 & 57.8 & 54.0 & 61.6 & 56.9 & 53.6 \\
\hline
\end{tabular}

Varian, Palo Alto, USA). As PAHs mobilized from the treated sediments were at trace levels into the aqueous effluents, a solid phase extraction (SPE) step was performed before HPLC analysis. After conditioning a SPE cartridge containing $60 \mathrm{mg}$ of sorbent (STRATA X, Phenomenex), the aqueous effluent was percolated, rinsed and PAHs were eluted with $5 \mathrm{~mL}$ of methylene chloride. $60 \mu \mathrm{L}$ of dimethylsulfoxide was added as a keeper before a complete evaporation under a nitrogen flow, followed by a solubilisation in $1 \mathrm{~mL}$ of acetonitrile. This SPE step enabled to purify the sample and to obtain concentration factors from 20 to 100 . $20 \mu \mathrm{L}$ of the final extract was injected in the HPLC system, on a PP Envirosep column $(150 \times 4.6 \mathrm{~mm}, 5 \mu \mathrm{m}$ particles $)$ from Phenomenex, with a mobile phase composed of acetonitrile/water $55 / 45(\mathrm{v} / \mathrm{v})$ during $5 \mathrm{~min}$, followed by a linear gradient for $20 \mathrm{~min}$, to finish with $100 \%$ acetonitrile (flow rate: $1 \mathrm{~mL} \min ^{-1}$ ). Selected excitation and emission wavelengths for optimal fluorimetric detection of PAHs were $250 / 370 \mathrm{~nm}$ for phenanthrene, $235 / 420 \mathrm{~nm}$ for fluoranthene and pyrene, $267 / 385 \mathrm{~nm}$ for chrysene and $260 / 420 \mathrm{~nm}$ for benzo[b]fluoranthene.

\section{Metals analysis}

Samples of the model sediment were freeze-dried at $-80{ }^{\circ} \mathrm{C}$, as defined in the standard ISO 16720:2005 (lyophilizer Lyovag GT2, STERIS Corporation, Mentor, USA), then grounded and sieved through apertures of $200 \mu \mathrm{m}$. For metals extraction, $0.5 \mathrm{~g}$ duplicate subsamples were weighed into digestion tubes (ISO 12914). Digestion of samples was performed using $8 \mathrm{~mL}$ aqua regia (mixture of nitric and hydrochloric acids) and $2 \mathrm{~mL}$ pure water, in closed PTFE vessels, using a microwave accelerated reaction system (Mars X, CEM Corporation, Matthews, USA), in three stages with $70 \%$ power alternating with two cooling stages. Mineralized solutes were transferred into $100 \mathrm{~mL}$ volumetric flasks and completed with pure water. After shaking, samples were centrifuged $(7 \mathrm{~min}$, 9,000 rpm) and supernatants were filtered with a Phenex Teflon PTFE filter $(0.45 \mu \mathrm{m})$ before analysis. The metal concentrations were analyzed using an electrothermal atomic absorption spectrometer (ETAAS) (Spectra A220Z-GTA-110Z, Varian Corporation, Palo Alto, USA). Metals in cathodic and anionic aqueous effluents were also analyzed by ETAAS after their filtration with a PTFE filter.

\section{Results and discussion}

Enhancing agents are necessary to increase the removal, by the electrokinetic process, of organic and metal compounds bound on fine-grained sediments, where clayey fine particles and organic matter strongly sorb and concentrate these contaminants. Suitable flushing solutions had to be selected in order to play different roles, in the context where PAHs and metals both existed in our studied aged model sediment: additives allowing to maintain an acidic $\mathrm{pH}$ (nitric acid, acetic acid...) or forming soluble complexes with metals (citric acid, EDTA...) proved to be effective for metal removal (Wang et al. 2007; Giannis et al. 2009; Alcantara et al. 2010; Kim et al. 2011). Furthermore, maintaining a basic $\mathrm{pH}(\mathrm{NaOH}, n$-butylamine...) or using solubilizing compounds such as surfactants (Tween 80, Igepal CA-720, sodium dodecyl sulfate, alkylpolyglucosides...) or cyclodextrins proved to be effective for $\mathrm{PAH}$ removal (Reddy et al. 2006; Giannis et al. 2007; Pazos et al. 2010). In our case, the final objective being to insure a simultaneous good removal of both species, we chose to dismiss additives which maintain a basic $\mathrm{pH}$, in order to avoid poor metal removals (Maturi and Reddy 2008).

So nitric acid was tested as being a strong acid, because it was less tested in the context of PAHs removal. Citric acid was selected as being a weak acid, but also for its effectiveness to form complexes with metals (Nogueira 
et al. 2007) and (which is less discussed) for its ability to change the phase properties of OM and to facilitate PAHs release (Yang et al. 2001). SDS and Tween 20 were chosen as anionic and nonionic surfactants (respectively) and although they have been already tested alone in previous studies, they have not been tested when mixed with other enhancing agents. At last, it must be mentioned that all the tested flushing reagents (pure or mixed) were introduced at the same time into the anodic and the cathodic compartments, which is quite unusual. Indeed, acids and complexing agents are generally introduced at the cathode reservoir and surfactants at the anode reservoir. But recently, Genc et al. (2009) showed that the control of $\mathrm{pH}$ at both electrode cells led to a less fluctuating electroosmotic flow during the EK treatment, which seems to be better for the removal of organic species. Moreover, considering that electroosmotic flow could be reversed in some cases (Genc et al. 2009), we chose to introduce the PAHs solubilizing agents at the two electrode cells.

Variation of electric parameters and model sediment characteristics

The measured electric current for all the electrokinetic tests is plotted as a function of time for different EK test conditions in Fig. 2a. The results showed that the current values fluctuated strongly at the beginning of the test when nitric acid (NA) or high contents of $\mathrm{NaCl}$ were added in the aqueous processing fluid. The value of electric current remained stable after 6 days of treatment for all tests and was quite low, reaching a value less than $10 \mathrm{~mA}$, except for the test conducted with NA, where current remained five times higher. The lowest value for electrical current was observed for deionized water (DW). For the treatments with $\mathrm{NA}$ and $\mathrm{NaCl}$, the behavior is explained by a high ionic strength which promotes a high electric current at the beginning of the treatment. NA helps to solubilize various organic and inorganic species contained in the model sediment, leading to the rise of the electric current (and conductivity). Then, current value gradually decreases because of the neutralization of migrating cationic and anionic ions. Cations migrating towards the cathode (comprising also $\mathrm{H}^{+}$, due to water electrolysis) can be neutralized by anions migrating towards the anode (comprising also $\mathrm{OH}^{-}$, due to electrolysis). In the case of aqueous solutions containing high contents of $\mathrm{NaCl}$, a peak value was observed after a few hours of treatment, which decreased quickly after only 1 day. The strong initial ionic strength, due to the dissociation of $\mathrm{NaCl}$, decreased drastically because of changes occurring in sediment $\mathrm{pH}$ (as will be discussed later), which cause a global chemical precipitation and consequently a strong depletion of mobile ionic species. For the processing fluids introducing additional non-reactive ions (citric acid (CA) or SDS), the value of electrical current was slightly higher than the one obtained with DW. Adding only Tween 20 (TW20), a nonionic species, obviously did not help to improve the electrical current compared to DW. In the case of mixtures of CA + SDS and CA + TW20, the electrical current was higher than with pure water but less than when using only $\mathrm{CA}$, in the order $\mathrm{CA}>\mathrm{CA}+\mathrm{TW} 20>\mathrm{CA}+\mathrm{SDS}>$ water.

Figure $2 b$ shows the electroosmotic flow (EOF) measured for all tests. Electroosmosis is closely related to sediment properties: it is the movement of water relative to the sediment charged solid grains under the influence of an electric gradient. When the surface is negatively charged, water flows to the cathode. It is the case of our model sediment, which contains kaolinite, silt and sand whose surface charges are negative at the initial $\mathrm{pH}(\mathrm{pH}=6.8)$. Total EOF was lowest when processing fluids contained deionized water or SDS, and was increasing in the order: $\mathrm{DW} \approx \mathrm{SDS}<\mathrm{NaCl} \approx \mathrm{CA}+\mathrm{TW} 20<\mathrm{TW} 20 \approx-$ $\mathrm{NA} \approx \mathrm{CA}+\mathrm{SDS}<\mathrm{CA}$. The average electrolyte flowrate was the fastest when $\mathrm{CA}$ was used $\left(88.2 \mathrm{~mL}\right.$ day $\left.^{-1}\right)$. Indeed, it was already reported that citric acid could significantly increase EOF (Peng and Tian 2010). But when mixed with SDS or TW20, CA was less effective in increasing EOF. The average electrolyte flow-rate was decreased to $29.1 \mathrm{~mL}^{-1}{ }^{-1}$ when mixing SDS with CA and to $18.1 \mathrm{~mL} \mathrm{day}^{-1}$ when mixing TW20 with CA. It must be pointed out that cumulative EOF presented in Fig. $2 b$ is the sum of flows towards the cathode and the anode. However, migration flows towards each of the electrodes are in opposition, and inversions of global EOF could be observed during some EK tests: it was particularly the case when adding $\mathrm{NaCl}$, where the flow towards the anode was predominant after a few days of experiment, and also, to a lesser extent, when DW or SDS were used as processing fluids. It is known that inversions of EOF can be detrimental to organic pollutant removals. For all the other tests, the flow towards the cathode was dominating. At last, even if the global EOF was greater when employing the mixture SDS + CA than with the mixture TW20 + CA, it cannot augur a better PAHs removal, because we must take into account that PAHs can be solubilized into the anionic micelles, which counteract the global flow towards the cathode.

Figure 3a shows the final distribution of electrical conductivity (EC) within the model sediment after each EK treatment. The initial model sediment EC was $932 \mu \mathrm{S} \mathrm{cm}^{-1}$ when mixed with DW and $4,580 \mu \mathrm{S} \mathrm{cm}^{-1}$ when mixed with salt water. Sediment EC changed drastically at the end of two tests, with $\mathrm{NaCl}$ and NA as processing fluids. For the test with $\mathrm{NaCl}$, the electrical conductivity remained markedly higher than that with DW, 
Fig. 2 Variations of a electric current and $\mathbf{b}$ cumulative electroosmotic flow with elapsed time and with different processing fluids
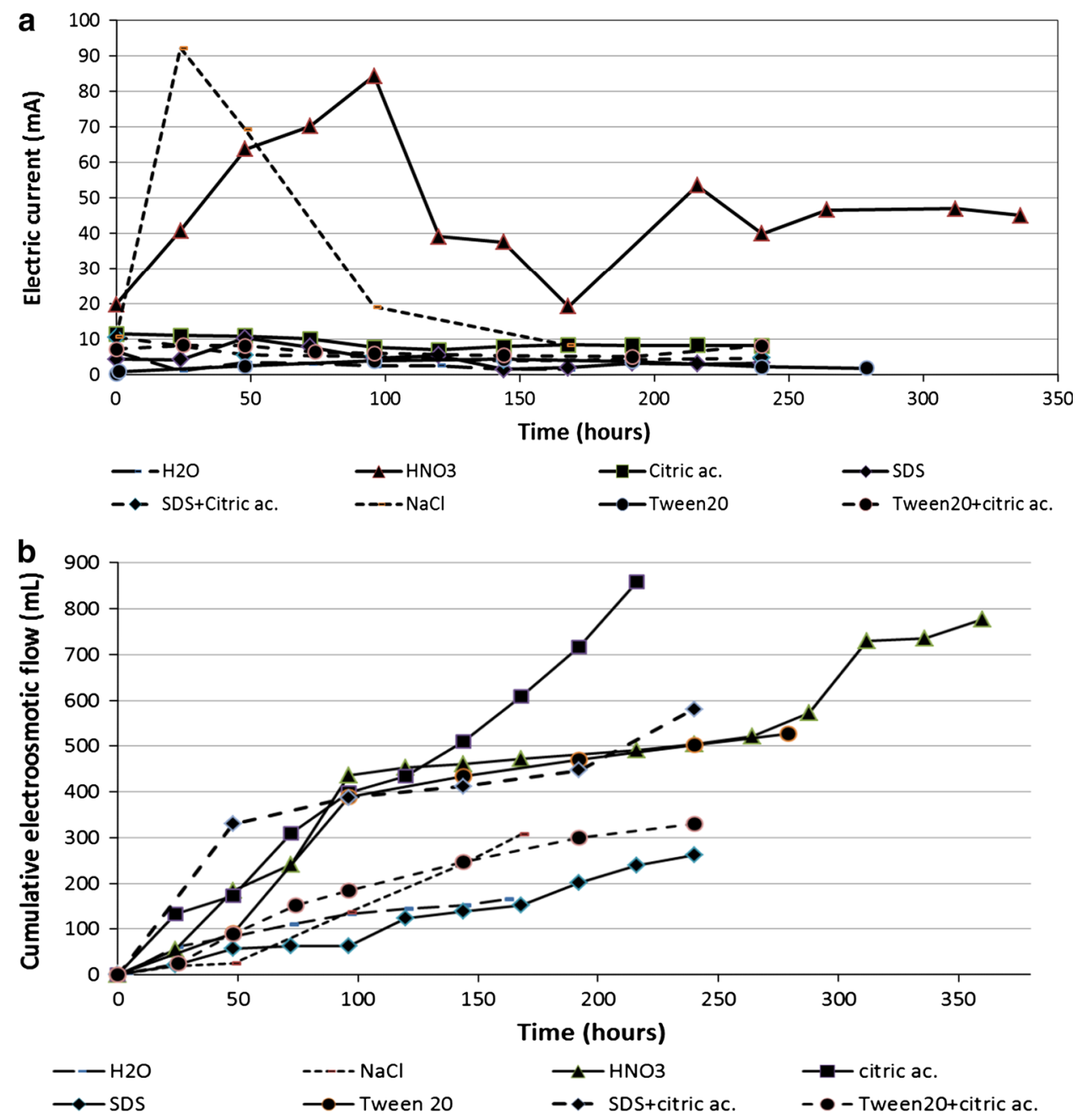

but important dissimilarities could be noted at both ends of the model sediment specimen. EC remained high near the anode while EC dropped near the cathode. Even if less pronounced, this tendency could be observed for treatments with TW20, TW20 + CA and SDS + CA. For the test with NA, the highest model sediment EC was observed in the middle column and decreased towards both ends. EC drop, generally observed near the cathode, is a result of ion precipitation. Indeed, in the electric field, $\mathrm{H}^{+}$migrates towards the cathode more quickly than $\mathrm{OH}^{-}$, which migrates towards the anode. Consequently, there is an accumulation of $\mathrm{OH}^{-}$near the cathode reservoir and metals form hydroxides that precipitate, which lead to a lower EC. In contrast, the acidification of a larger zone of the sediment at the anode side contributes to a dissolution of minerals and thus to a larger EC. In the case of the EK treatment with NA, the model sediment section just near the anode reservoir shows also an EC drop. It is certainly because this treatment was longer than the others: dissolved metals were all removed from this section and EC was consequently low.
Figure $3 \mathrm{~b}$ shows the $\mathrm{pH}$ values which were measured in the model sediment after each EK treatment. As can be seen, a treatment with DW led to an important acidification of sediment near the anode $(\mathrm{pH}=2.9)$ and an increase of $\mathrm{pH}$ near the cathode $(\mathrm{pH}=10.0)$. This tendency was more pronounced by adding $\mathrm{NaCl}$ in the processing fluid: $\mathrm{pH}$ reached 2.0 near the anode and 11.4 near the cathode. As already discussed, electrical current was higher with this saline processing fluid and all the phenomena were accelerated (electomigration, electrolysis...). The apparition of a basic front leads to EC and current drops and slows down or stops the electromigration of cations towards the cathode. Using the strong NA as a processing fluid helps to maintain an acidic $\mathrm{pH}$ along the sediment specimen, contributing to a high electrical conductivity, high values of electrical current and permitting to keep metallic contaminants in the dissolved aqueous phase. Nevertheless, when the $\mathrm{pH}$ becomes too low, reversed EOF may occur and opposing EOF to the electromigration of cationic species or reversing the migration direction of neutral species is detrimental to the decontamination process (Kaya and 
Fig. 3 Distributions of a electrical conductivity and b $\mathrm{pH}$ within sediment after EK treatments with different electrolytes
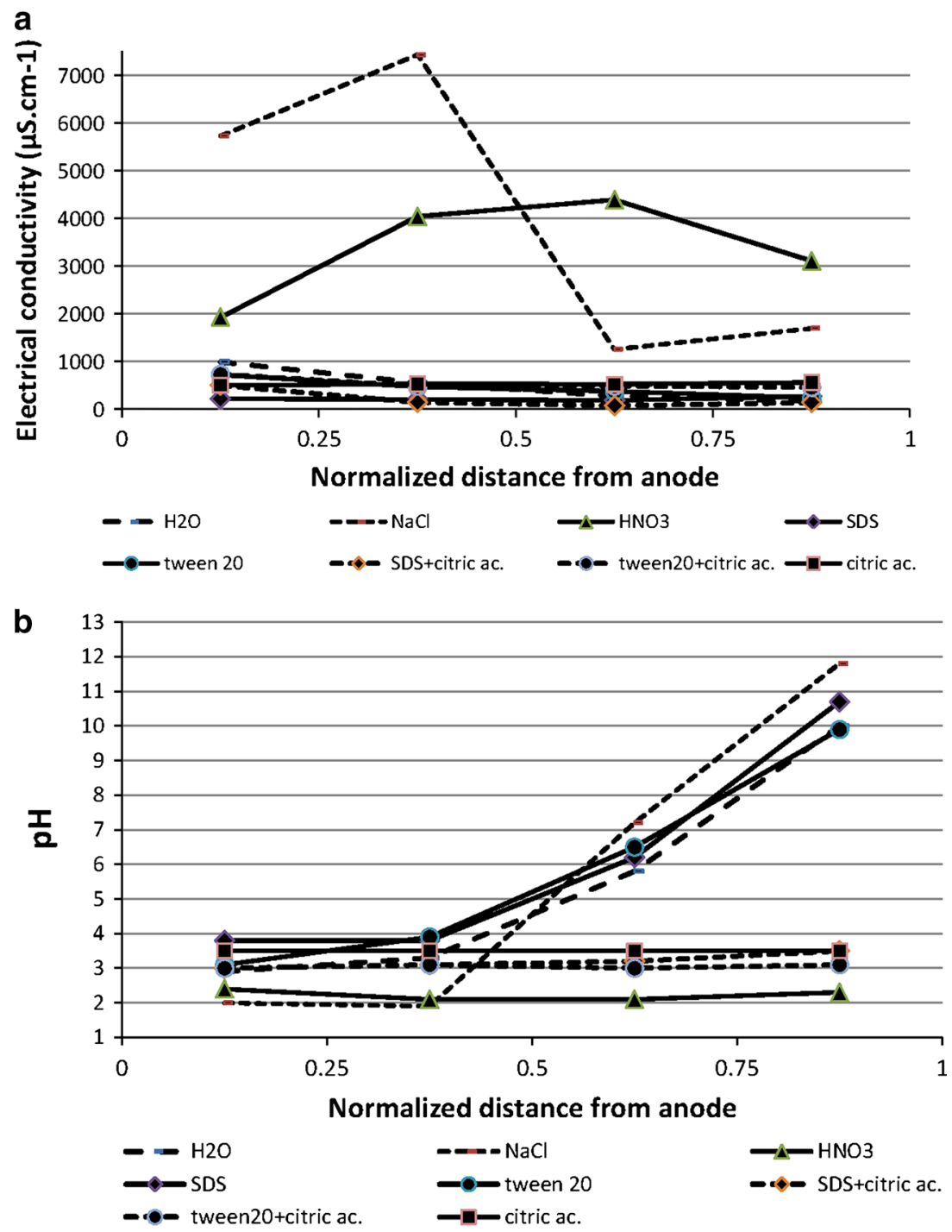

Yukselen 2005). Consequently, it is necessary to maintain a $\mathrm{pH}$ low enough to keep metallic contaminants dissolved but high enough to maintain a negative zeta potential. It is why citric acid was also chosen for other tests, as a weaker acid with a buffering capacity. Adding CA in the processing fluid led to a stabilization of the $\mathrm{pH}$ from the anode to the cathode, between 3.0 and 3.5 for EK4, EK7 and EK8 tests, even when mixed with surfactants. Lastly, processing fluids containing only surfactants obviously did not enable to maintain the acidic $\mathrm{pH}$ near the cathode.

\section{Removal of metals}

Figures 4 and 5 show, respectively, the residual distribution of $\mathrm{Zn}$ and $\mathrm{Cu}$ in the model sediment treated with the different processing fluids. Final distributions were also determined for $\mathrm{Cd}, \mathrm{Cr}$ and $\mathrm{Pb}$ (data not shown). All the metals were also measured in liquid effluents (anode and cathode) during each EK treatment (data not shown).
Table 3 indicates that in the mass balance, metal losses or excesses could be measured, for many reasons. As a general rule, the analytical process (extraction, filtration, detection...) contributes to a large extent to the uncertainty of the results (losses or excesses compared to initial values introduced into the model sediment). In many cases, aqua regia could lead to better extractions after an EK treatment, because of changes in metal speciation (Ryu et al. 2011). Uncertainties can also be attributed to important sediment mass changes after some treatments (dissolution of organic matter, mass increase because of excesses of organic additives...) (Nystroem et al. 2006).

A general trend is that $\mathrm{Zn}$ was the easier metal to be removed from the model sediment, whatever the treatment considered, whereas $\mathrm{Cr}$ and $\mathrm{Cu}$ were often the most difficult elements to be removed. As can be seen on Figs. 4a and 5a, the treatment with DW was not effective for removing metals from the model sediment. Metals tended 
Fig. 4 Distribution of $\mathrm{Zn}$ in sediment after EK treatments using different electrolytes a DW and salt water $\mathbf{b}$ NA, CA, SDS and TW20 $\mathbf{c}$ mixtures of $\mathrm{SDS}+\mathrm{CA}$ and TW20 + CA

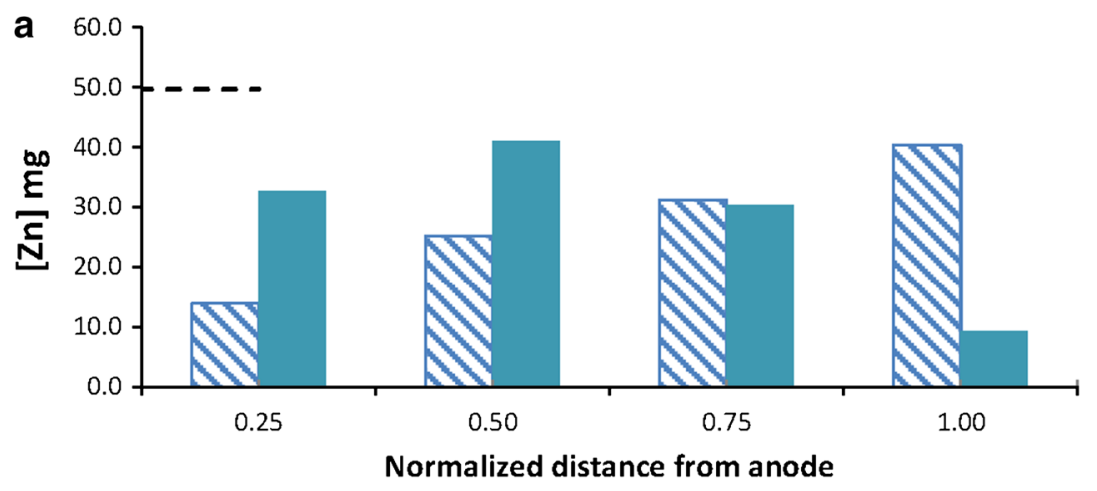

$\$$ water salt water - - - initial Zn

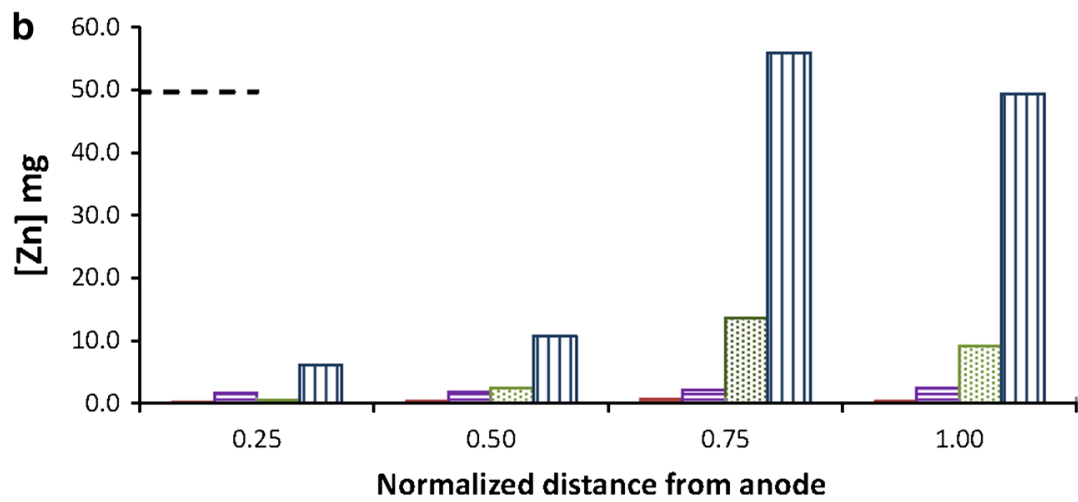

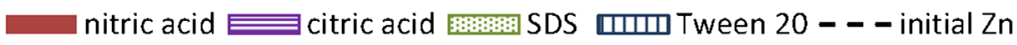

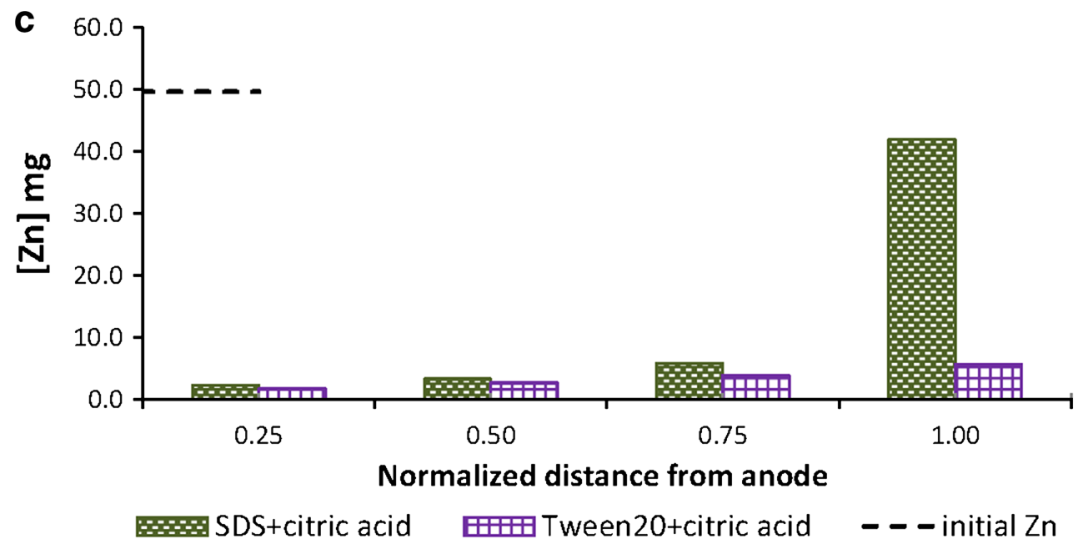

to accumulate near the cathode because of the apparition of the alkaline front, causing their precipitation as a result of the formation of hydroxides. This excess of metals in the sediment section near the cathode is a focusing effect of EK treatments when no control of the $\mathrm{pH}$ is implemented through acidic flushing solutions. Indeed, Pourbaix diagrams show that around electric voltages of $1 \mathrm{~V}, \mathrm{Cd}, \mathrm{Zn}$, $\mathrm{Cu}, \mathrm{Cr}$ and $\mathrm{Pb}$ form neutral precipitates of oxides or hydroxides at respectively $\mathrm{pH}>8.1, \mathrm{pH}>6.8, \mathrm{pH}>5$, $\mathrm{pH}>4.5$ and $\mathrm{pH}>4$. So $\mathrm{Zn}$ tends to precipitate at $\mathrm{pH}$ above 7, whereas $\mathrm{Cu}, \mathrm{Cr}$ and $\mathrm{Pb}$ precipitate at lower $\mathrm{pH}$. Therefore, when the alkaline front appears, $\mathrm{Cu}, \mathrm{Cr}$ and $\mathrm{Pb}$ are more rapidly immobilized near the cathode than $\mathrm{Zn}$.
For this reason, the best removals were obtained in the order $\mathrm{Zn}>\mathrm{Cr}>\mathrm{Cu}>\mathrm{Pb}>\mathrm{Cd}$ with $\mathrm{DW}$. Other mechanisms can explain the low mobilization of metals from sediments. In the case of $\mathrm{Cd}$, its preferential binding to $\mathrm{OM}$ can explain its lowest removal, compared to other metals, although it precipitates at more alkaline $\mathrm{pH}$. It has been shown that adsorbabilities of sediments to metals increased in the order $\mathrm{Zn}<\mathrm{Pb}<\mathrm{Cu}<\mathrm{Cr}$ (Lin and Chen 1998), but the behavior of $\mathrm{Cd}$ strongly depends on the nature and content of OM, and on the respective total metal concentration in soils or sediments. In fact, $\mathrm{Cd}$ is often described as a metal easy to desorb from sediments (Nystroem et al. 2005). But here, Cd is markedly less concentrated than the 
Fig. 5 Distribution of $\mathrm{Cu}$ in sediment after EK treatments using different electrolytes a DW and salt water $\mathbf{b}$ NA, CA, SDS and TW20 c mixtures of $\mathrm{SDS}+\mathrm{CA}$ and TW20 + CA
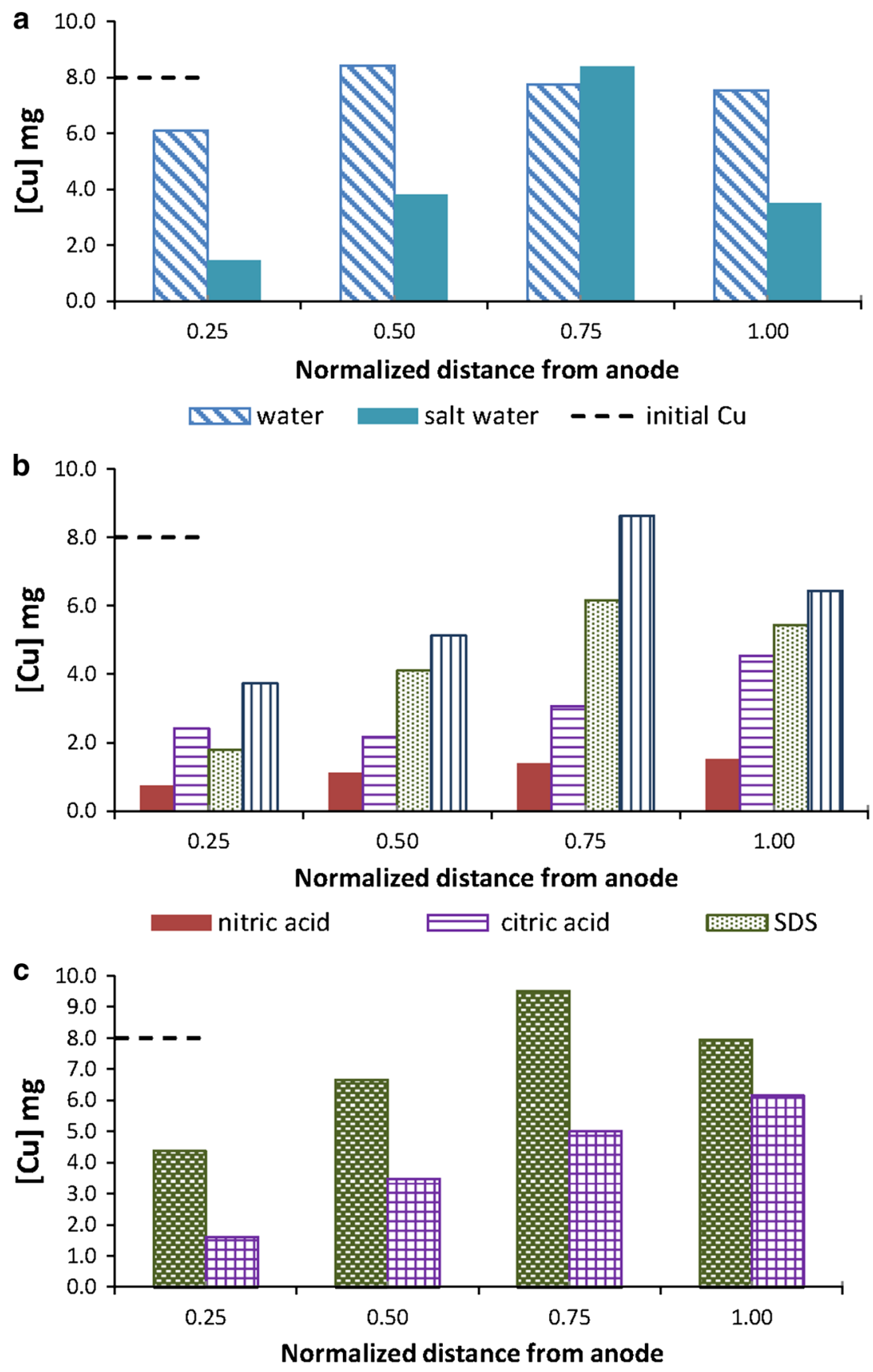

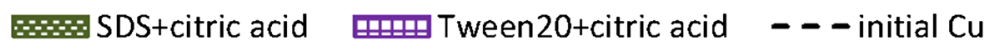

other metals and its presence in the exchangeable fraction of the model sediment, which is the fraction easier to mobilize, is certainly less important than its organic-bound fraction, this latter fraction being particularly difficult to extract or mobilize.

In Figs. 4a and 5a, we can see that salinity changes the distribution of metals after completion of the experiment. Salinity generally increases the mobility of metals and consequently their removal. Actually, we can see on Table 2 that the removal of metals in EK2 treatment was better than EK1 treatment. When adding high contents of
$\mathrm{NaCl}$ in the pore fluid, the best recoveries were obtained in the order $\mathrm{Pb}>\mathrm{Cu} \approx \mathrm{Zn} \approx \mathrm{Cr}>\mathrm{Cd}$. It was stated that an increase of salinity though addition of $\mathrm{NaCl}$ promoted a higher release of $\mathrm{Pb}$ than of $\mathrm{Cu}$ and $\mathrm{Zn}$ from soils (Acosta et al. 2011). It was particularly obvious in our test for $\mathrm{Pb}$, but in the case of $\mathrm{Zn}$, its removal remained unchanged. The higher electrical current and sediment conductivity were responsible for a rapid migration of solubilized metals at the first stage of the treatment with $\mathrm{NaCl}$, but unfortunately, metals were rapidly stopped by the formation of the alkaline front near the cathode. As can be seen on Figs. 4a 


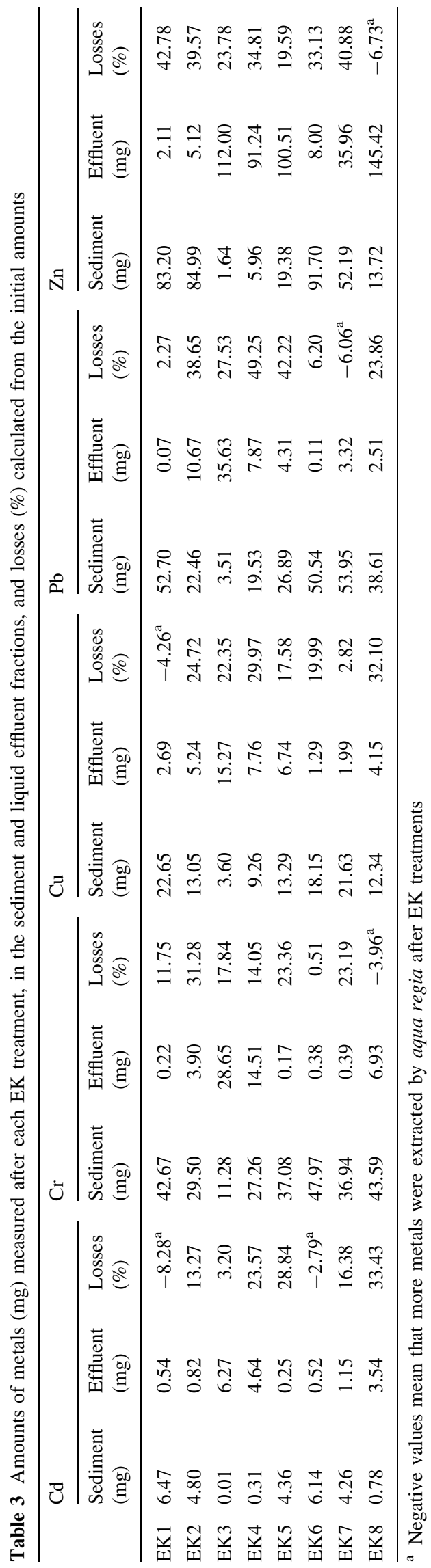

and $5 \mathrm{a}$, metals were focused in the middle of the model sediment specimen.

Using NA as an additive led to important metal recoveries from the model sediment, from 77 to $99.9 \%$. Figures $4 \mathrm{~b}$ and $5 \mathrm{~b}$ show a better removal of $\mathrm{Zn}$ compared to $\mathrm{Cu}$. We can see on Table 2 that when NA was used, the best recoveries were obtained in the order $\mathrm{Zn} \approx \mathrm{Cd}>\mathrm{Pb}>\mathrm{Cu}>\mathrm{Cr}$. In the acidic medium, $\mathrm{Zn}$ which is generally predominantly found in the most accessible phases of the sediment (Kirkelund et al. 2010) can be completely removed after 15 days of treatment, and $\mathrm{Cd}$ also. In this latter case, $\mathrm{OM}$ (which is an immature organic matter, with no elemental carbon fraction) was probably completely dissolved by the strong acid and $\mathrm{Cd}$ could be released and thus could easily migrate. Now, if we compare the removal of $\mathrm{Pb}$ when using pure water or $\mathrm{NA}$, we could note that the absence of the basic front, when $\mathrm{pH}$ is stabilized around 2.0 by NA, promoted its effective migration towards the cathode, whereas $\mathrm{Pb}$ was essentially found in the anodic effluents when DW was used. Lastly, $\mathrm{Cu}$ and $\mathrm{Cr}$ are less mobile than the other metals when using NA in the processing fluid, because they are mainly found in the oxidisable fraction of sediments, less accessible for electromigration processes (Kirkelund et al. 2010).

The fourth treatment EK4 consisted in adding CA to the processing fluid. EDTA is the most often used complexing agent, but it is toxic and poorly biodegradable compared to CA (Lestan et al. 2008). Other chelatants were tested for EK remediation, such as diethylenetriaminepentaacetic acid, nitrilotriacetic acid, diaminocyclohexanetetraacetic acid or ethylene glycol tetraacetic acid, whose removal efficiencies were not the same according to the metals considered (Giannis et al. 2009, 2010). The combined effect of solubilization of metals and metal-complexes at acidic $\mathrm{pH}$ are responsible for the removal capacities of chelatants. In our test, when using $\mathrm{CA}$ as an additive, metal removal efficiencies were better in the order $\mathrm{Zn} \approx \mathrm{Cd}>\mathrm{Pb} \approx \mathrm{Cu}>\mathrm{Cr}$, which is the same order as that found with NA. Figures $4 \mathrm{~b}$ and $5 \mathrm{~b}$ show that the final distribution of metals in the model sediment follows the same trend as with NA, that is to say a shift of the remaining metals towards the cathode. It could be noted from the analysis of the effluents that the metal removal towards the anode was also effective when using $\mathrm{CA}$. These results supported the conclusion that $\mathrm{Pb}, \mathrm{Cu}, \mathrm{Cd}$ and $\mathrm{Cr}$ complexes react with $\mathrm{CA}$ to form negative complexes migrating towards the anode. This migration of negatively charged complexes towards the anode was not so pronounced in the case of $\mathrm{Zn}$, which rather migrated towards the cathode as a free cation.

EK5 and EK6 treatments consisted in adding surfactants to the processing fluid, at concentrations well above their critical micellar concentration (CMC). As can be seen in Table 2, metal removal was better when adding the anionic surfactant SDS than using DW (Giannis et al. 2007). The 
effectiveness of the neutral surfactant TW20 for metal removal was worse than that of SDS. A mechanism which can explain the better extraction of metals when adding the anionic surfactant in water is counter-ion exchange: dissolved cationic metals can exchange with $\mathrm{Na}^{+}$on SDS micelles and are transported towards the anode. Indeed, the five metals were found predominantly in anodic effluents and less in the cathodic chamber when using SDS as an additive. When migration towards the cathode is stopped, due to the apparition of the alkaline front, the migration towards the anode can go on, thanks to SDS micelles. Unfortunately, the development of the very basic $\mathrm{pH}$ near the cathode tends also to cause SDS precipitation in a large part of the model sediment specimen and results in stopping the metal removal. We emphasized that the nonionic surfactant was less effective than the anionic one to remove metals. Obviously, metal adsorption on the neutral micelles was not possible and TW20 only slightly enhanced metal removal compared to pure water (except for $\mathrm{Cr}$ ), because the surfactant lowered the surface and interfacial tensions and desorption processes from the solid matrix could be slightly improved.

In both cases, adding surfactants without any control of $\mathrm{pH}$ led to the apparition of the basic front, with a consecutive precipitation of metals and a poor total metal removal. Consequently, it seemed more interesting to add these surfactants mixed with $\mathrm{CA}$, in order to maintain an acidic $\mathrm{pH}$ (below $\mathrm{pH}=4$ ) along the sediment specimen. However, no metal removal improvement, compared to the treatment with SDS alone, was observed when mixing SDS + CA (Table 2). CA did not help $\mathrm{Cd}$ and $\mathrm{Cr}$ removal when mixed with SDS (EK5 and EK7 treatments provide the same results) and the mixture of these two additives even causes an important decrease of $\mathrm{Cu}, \mathrm{Pb}$ and $\mathrm{Zn}$ removals. Indeed, the migration of SDS is in opposition to the electromigration of the free solubilized cations, which can explain the negative effect of mixing CA and SDS. The combination of TW20 and CA was more favorable to metal removal than the combination with the anionic surfactant. Alcantara et al. (2012) actually demonstrated that the combination of a chelatant and a nonionic surfactant was particularly interesting for simultaneous removal of metals and organic pollutants from soils. In our case, the levels reached for metal removal in presence of mixed CA and TW20 were below those obtained with CA alone and markedly above those obtained with TW20 alone. In fact, TW20 was not really responsible for metal removal but affected citric acid efficiency by decreasing the total EOF and electrical current compared to tests with $\mathrm{CA}$ alone. In conclusion, surfactants did not help metal removal when mixed with the acidic chelatant and the combination with the anionic surfactant was particularly unfavorable.

\section{Removal of PAHs}

It is well known that it is particularly difficult to remove PAHs from soils or sediments, because such contaminants possess low water solubility and high soil organic carbon/water partition coefficients $\left(\mathrm{K}_{\mathrm{oc}}\right)$. Indeed, PAHs have a tendency to strongly bind with the clay minerals and organic matter present in sediments. To improve the electrokinetic process, it seems necessary not only to enhance PAHs desorption and their solubilization in the aqueous phase, but also to create a favorable environment to transport them towards the electrode compartments (by increasing EOF for example). Wang et al. (2007) described other mechanisms than electroosmosis to explain the migration of lipophilic neutral compounds, such as "uplifting effect" (transport of nonionic contaminants in an immiscible non-aqueous liquid phase pushed in the same direction as the pore water flow) or dielectrophoresis (movement of an electrical dipole formed in non-uniform electric field). All these phenomena could explain why a proportion of PAHs could be removed from our model sediment using only DW (Table 2). EK2 treatment, with added $\mathrm{NaCl}$, did not really change the results for PAHs. However, adding nitric acid caused higher PAHs removal efficiencies. It is a fact that EOF was higher when adding NA to the processing fluid (Fig. 3b), but electroosmotic flow alone could not explain these high removal levels. As described previously, it is likely that the high content of NA permitted to dissolve $\mathrm{OM}$, and thus to desorb a high portion of PAHs. So "uplifting effect" could be at its maximum to transport them through their solubilization in the non-aqueous non-miscible organic phase. Adding the weaker citric acid did not allow dissolving OM, and PAH removals were identical to those obtained with DW, even if EOF was greater. Thus, EK4 treatment shows that the EOF is not a sufficient "force" to remove strongly sorbed non soluble organic contaminants: desorption and solubilization steps are essential before the electrokinetic transport.

Surfactants were good candidates, not only to enhance PAHs desorption from solid particles, but also to enhance PAHs solubility in the aqueous medium, by partitioning them into the hydrophobic core of micelles. But surfactants can also be sorbed by the sediment matrix, which lead to PAH partitioning into immobilized sorbed surfactants (ad-micelles or hemi-micelles) and consequently to an increase of PAHs sorption onto soils. Cationic surfactants are not suitable for soil remediation because they are strongly retained by negative charges of the soil surface. Anionic surfactants generally have a low degree of sorption on soils or sediments, but they are less economical, because their critical micellar concentration 
(CMC) is higher. Nonionic surfactants can be chosen, because they are less sorbed onto soil particles than cationic ones, and they have high solubilization capacities at low concentration (because of their low CMC). Moreover, they have a higher biodegradability in the environment (Pazos et al. 2010). The choice of surfactant concentration is a critical point: on the one hand, its concentration must be high enough to form micelles within the interstitial solution, knowing that the concentration must be significantly higher than the CMC (because of competitive sorption on sediment particles) and on the other hand, the concentration must be low enough to avoid two detrimental effects for PAHs removal:

- EOF is decreasing as the concentration of nonionic surfactant increases (Yang et al. 2005);

- electrochemical oxidation of organics will happen (Gomez et al. 2009), and in relation to a given quantity of electricity, oxidation of the surfactant competes with oxidation of the PAHs, which is not favorable for PAH elimination by degradation.

For all these reasons, the anionic and less sorbed surfactant was tested at 5 times its CMC and the nonionic one at 50 times its CMC, which represents a solution concentration of $0.5 \%$, that is not high compared to other studies (Maturi et al. 2009).
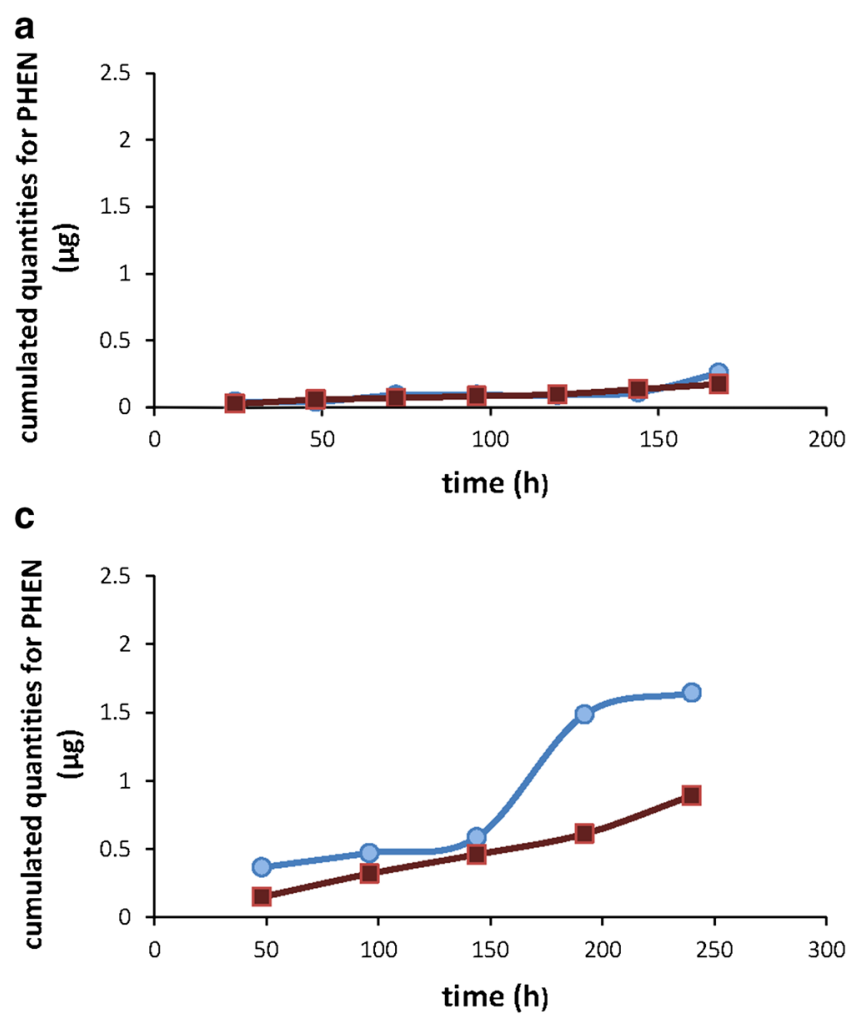

If we compare the results obtained when adding SDS or TW20 in the processing fluid (Table 2), we can see that the nonionic surfactant enhanced significantly the PAHs removal compared to pure water but surprisingly, the anionic surfactant SDS had a bad influence on PAHs removal. We noted on Fig. $3 b$ that EOF was the lowest when using SDS as an additive, so the conjunction of several phenomena could explain the detrimental effect of SDS on the model sediment decontamination: on the one hand, SDS is anionic and it migrates predominantly towards the anode, which counteracts the EOF; on the other hand, it was reported that the PAHs solubility enhancement of SDS above the CMC was not as important as this of nonionic surfactants (Zhu and Fen 2003). EK7 test, which consisted of mixing SDS and CA, permitted to slightly enhance PAH removals compared to SDS alone, certainly because of the increase of EOF, but results were not significantly better than with DW.

As mentioned previously, the addition of the nonionic TW20 permitted to obtain a higher EOF than when using SDS and since this neutral surfactant migrates with EOF, PAH removals were better. Figure 6 shows that phenanthrene was more likely to be found in the cathodic effluents when TW20 was used, whereas it was found more in anodic effluents when SDS was used. It must be noted at this point of the discussion that PAHs are rarely
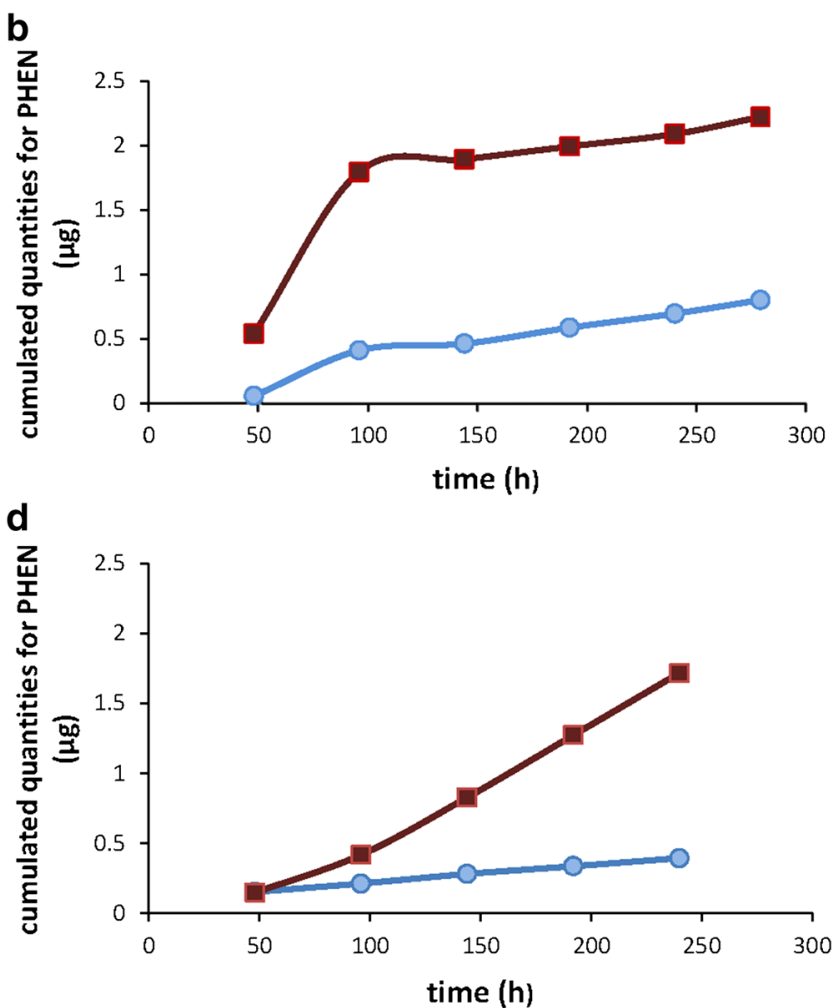

Fig. 6 Cumulated quantities of phenanthrene recovered in aqueous anodic (open circle) and cathodic (filled square) effluents during different EK treatments a DW b TW20 c SDS + CA d TW $20+$ CA 
Fig. 7 Distribution of PAHs in sediment after EK treatments using different electrolytes a NA b SDS + CA c $\mathrm{TW} 20+\mathrm{CA}$

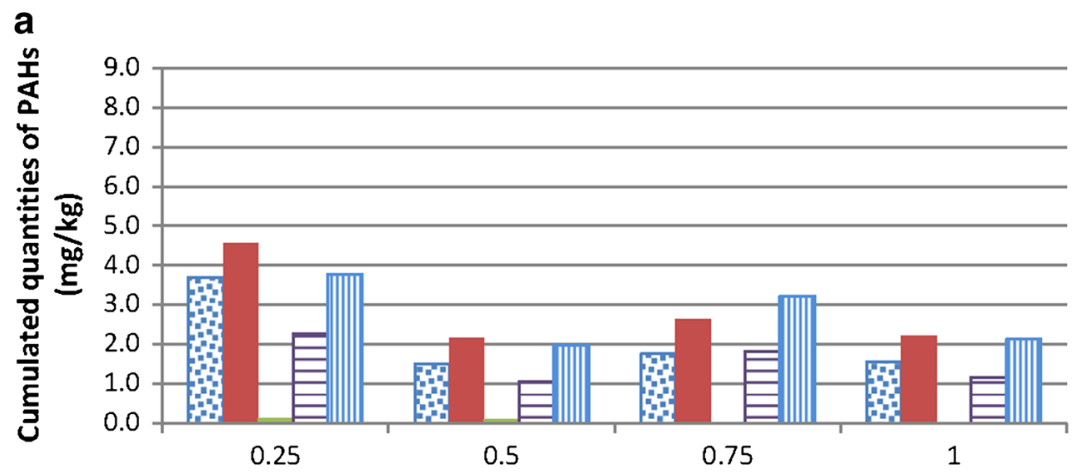

Normalized distance from anode

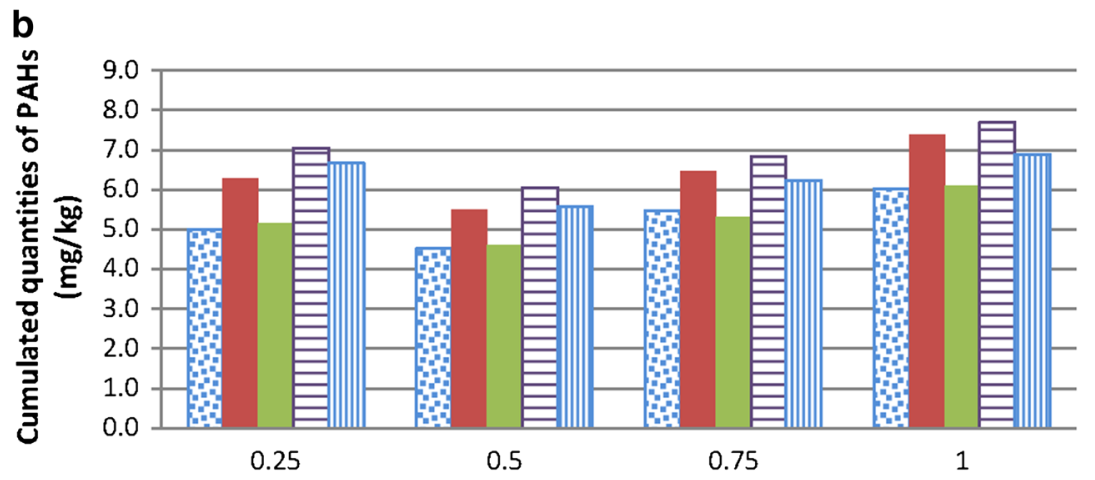

Normalized distance from anode

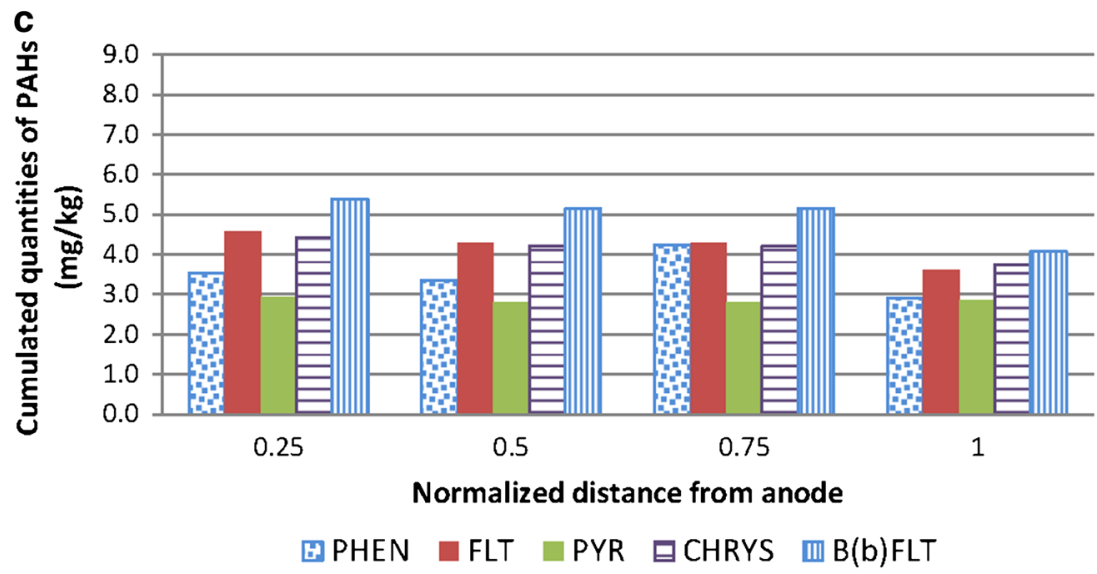

quantified in the aqueous effluents during an EK treatment, probably because they are found at trace levels. The development of an original method coupling purification and trace enrichment by SPE, and then separation and quantification by HPLC-FLD (see "Chemical analysis" section) allowed us to follow their evolution in the aqueous effluents during each EK treatment. In this way, we could observe that all the removed PAHs from the model sediment could not be found quantitatively in the aqueous effluents. Indeed, Fig. 6a shows that the amounts of PAHs quantified in DW effluents were extremely low, because PAHs probably precipitated into electrode reservoirs, due to their low aqueous solubility. Moreover, recovered quantities of PAHs in electrode cells were not extremely higher when using TW20 than those recovered with DW, although PAHs were more efficiently removed from the model sediment. Indeed, we observed solid agglomerates near the electrode surfaces in which PAHs were certainly precipitated, but they were not analyzed and quantified.

EK8 test showed that mixing CA and TW20 did not affect PAHs removals compared to the use of TW20 alone (Table 2), although EOF was decreased. Figure 7 shows the final distribution of PAHs into the model sediment specimen for EK3, EK7 and EK8 tests, which were performed with NA and with mixtures of CA and surfactants. The tendency is that PAHs were better removed near the anode when SDS was present in the processing fluid (even 
if the global effectiveness is significantly lower than when using TW20 or NA), and PAHs were better removed near the cathode when NA or TW20 were used as flushing reagents. It is difficult to predict which PAH will be better removed compared to others. As pointed out by Alcantara et al. (2009), the order of increasing desorption can be unexpected even though we know that low molecular weight PAHs are better solubilized in surfactant micelles than high molecular weight PAHs. In our case, the main "anomaly" resulted from the pyrene behavior, which is always better removed than the other PAHs in all the treatments tested. It was particularly pronounced with NA treatment, where pyrene was almost totally removed. It can probably be explained by chemical degradation, which is concomitant to electromigration. Indeed, redox potentials were measured in the model sediment specimen at the end of each test (data not shown) and oxidative conditions were predominant, except when $\mathrm{NaCl}$ was added into the processing fluid. It is well-known that oxidative conditions promote in situ degradation of organic compounds (Pazos et al. 2013). It appeared that the highest values of redox potential were obtained after treatments with NA, particularly towards the cathode. So, oxidation reaction could have happened and degradation rate of pyrene was certainly higher than that of the other PAHs.

\section{Conclusion}

Among all the flushing reagents tested for the simultaneous removal of PAHs and metals from a model sediment containing high contents of clays, nitric acid showed the best global effectiveness. Its capacity to acidify the model sediment allowed a massive solubilization of metals and hence their effective migration from the sediment to the cathodic compartment. Moreover, it was demonstrated that the removal of neutral PAHs was also improved when using the strong acid as an enhancing agent, due to its capacity to solubilize organic matter, to promote a good electroosmotic flow (despite an acidic $\mathrm{pH}$ and a reduced zeta-potential) and to generate oxidative conditions that may promote $\mathrm{PAH}$ degradation. However, NA is not recommended for in situ remediation. Mixtures of citric acid and surfactants (more environmental friendly than NA) were assessed since solubilization of organic contaminants and control of sediment $\mathrm{pH}$ are the critical factors, contributing to enhanced removal of both PAHs and metals. CA + SDS or CA + TW20 were tested for the first time together, and not sequentially. The association of CA to the nonionic TW20 showed interesting complementary effects for the simultaneous removal of both classes of contaminants. Although the presence of TW20 slightly decreased the removal of metals, the surfactant was essential for PAH decontamination. Only $\mathrm{Cr}$ removal was not enhanced with the association of these two additives, compared to the treatment with deionized water. On the other hand, the presence of CA did not change the PAH removal capacity of TW20. In contrast, the anionic surfactant SDS, associated to CA, was not a good candidate for the simultaneous remediation of PAHs and metals, because SDS migrates preferentially towards the anode, which counteracts the electroosmotic flow and the electromigration of free cations.

This study showed also that introducing the mixed additives in the two electrode cells was not detrimental, since good removals could be reached for the two classes of contaminants in less than 10 days of EK treatments.

In further studies, it could be interesting to test other mixtures of environmental friendly chelatants (such as ethylenediaminedissuccinate) and nonionic surfactants (alkyl polyglucosides...) on the natural dredged sediment from the French harbor disposal site. Biosurfactants could also be interesting to use, because of their high biodegradability, but also because some of them have not only surface active and micellisation properties, but also chelatant capacities (rhamnolipids, but also cyclolipopeptides). Finally, even if batch experiments are recommended to assess the actual performance of original mixtures of flushing additives, they do not represent the in situ conditions nor ex situ treatments accomplished in specially designed reactors. So, more research is needed to determine their effectiveness in field applications or in larger scale reactors.

Acknowledgments This study was supported by grants from the Haute Normandy Region (France) for RESSOLV project, through Norman SCALE research network. The authors thank W. Edmonds for his linguistic support.

\section{References}

Acosta JA, Jansen B, Kalbitz K, Faz A, Martinez-Martinez S (2011) Salinity increases mobility of heavy metals in soils. Chemosphere 85:1318-1324

Alcantara MT, Gomez J, Pazos M, Sanroman A (2009) PAHs soil decontamination in two steps: desorption and electrochemical treatment. J Hazard Mater 166:462-468

Alcantara MT, Gomez J, Pazos M, Sanroman MA (2010) Electrokinetic remediation of PAH mixtures from kaolin. J Hazard Mater 179:1156-1160

Alcantara MT, Gomez J, Pazos M, Sanroman M (2012) Electrokinetic remediation of lead and phenanthrene polluted soils. Geoderma 173-174:128-133

Al-Hamdan AZ, Reddy KR (2008) Transient behavior of heavy metals in soils during electrokinetic remediation. Chemosphere $71: 860-871$

Alzieu C (2005) Dredging and marine environment. Quae IFREMER, Versailles

Baboshin MA, Golovleva LA (2012) Aerobic bacterial degradation of polycyclic aromatic hydrocarbons (PAHs) and its kinetic aspects. Microbiology 81:639-650 
Benamar A, Baraud F (2011) Electrokinetic remediation of dredged sediments from Le Havre harbour. Eur J Environ Civ Eng $15: 215-228$

Bremner DH, Burgess AE, Chand R (2011) The chemistry of ultrasonic degradation of organic compounds. Curr Org Chem 15:168-177

Colacicco A, De Gioannis G, Muntoni A, Pettinao E, Polettini A, Pomi R (2010) Enhanced electrokinetic treatment of marine sediments contaminated by heavy metals and PAHs. Chemosphere 81:46-56

Froehner S, de Souza DB, Machado KS, Falcão F, Fernandes CS, Bleninger T, Neto DM (2012a) Impact of coal tar pavement on polycyclic hydrocarbon distribution in lacustrine sediments from non-traditional sources. Int J Environ Sci Technol 9:327-332

Froehner S, Dombroski LF, Machado KS, Scapulatempo Fernandes C, Bessa M (2012b) Estimation of bioavailability of polycyclic aromatic hydrocarbons in river sediments. Int $\mathrm{J}$ Environ Sci Technol 9:409-416

Gan S, Lau E, Ng H (2009) Remediation of soils contaminated with polycyclic aromatic hydrocarbons (PAHs). J Hazard Mater 172:532-549

Genc A, Chase G, Foos A (2009) Electrokinetic removal of manganese from river sediment. Water Air Soil Pollut 197:131-141

Giannis A, Gidarakos E, Skouta A (2007) Application of sodium dodecyl sulfate and humic acid as surfactants on electrokinetic remediation of cadmium-contaminated soil. Desalination 211:249-260

Giannis A, Nikolaou A, Pentari D, Gidarakos E (2009) Chelating agent-assisted electrokinetic removal of cadmium, lead and copper from contaminated soils. Environ Pollut 157:3379-3386

Giannis A, Pentari D, Wang JY, Gidarakos E (2010) Application of sequential extraction analysis to electrokinetic remediation of cadmium, nickel and zinc from contaminated soils. J Hazard Mater 184:547-554

Gidarakos E, Giannis A (2006) Chelate agents enhanced electrokinetic remediation for removal cadmium and zinc by conditioning catholyte pH. Water Air Soil Pollut 172:295-312

Gomez J, Alcantara M, Pazos M, Sanroman M (2009) A two-stage process using electrokinetic remediation and electrochemical degradation for treating benzo[a]pyrene spiked kaolin. Chemosphere 74:1516-1521

Kaya A, Yukselen Y (2005) Zeta potential of soils with surfactants and its relevance to electrokinetic remediation. J Hazard Mater 120:119-126

Kim KJ, Kim DY, Yoo JC, Baek K (2011) Electrokinetic extraction of heavy metals from dredged marine sediment. Sep Purif Technol 79:164-169

Kirkelund GM, Ottosen LM, Villumsen A (2010) Investigations of $\mathrm{Cu}, \mathrm{Pb}$ and $\mathrm{Zn}$ partitioning by sequential extraction in harbour sediments after electrodialytic remediation. Chemosphere 79:997-1002

Lestan D, Luo CL, Li XD (2008) The use of chelating agents in the remediation of metal-contaminated soils: a review. Environ Pollut 153:3-13

Lin JG, Chen SY (1998) The relationship between adsorption of heavy metal and organic matter in river sediments. Environ Int 24:345-352

Maturi K, Reddy K (2008) Cosolvent-enhanced desorption and transport of heavy metals and organic contaminants in soils during electrokinetic remediation. Water Air Soil Pollut 189:199-211

Maturi K, Reddy K, Cameselle C (2009) Surfactant-enhanced electrokinetic remediation of mixed contamination in low permeability soil. Sep Sci Technol 44:2385-2409

Mulligan CN, Yong RN, Gibbs BF (2001) An evaluation of technologies for the heavy metal remediation of dredged sediments. J Hazard Mater 85:145-163
Nogueira MG, Pazos M, Sanroman M, Cameselle C (2007) Improving on electrokinetic remediation in spiked Mn kaolinite by addition of complexing agents. Electrochim Acta 52:3349-3354

Nystroem GM, Ottosen LM, Villumsen A (2005) Electrodialytic removal of $\mathrm{Cu}, \mathrm{Zn}, \mathrm{Pb}$, and $\mathrm{Cd}$ from harbor sediment: influence of changing experimental conditions. Environ Sci Technol 39:2906-2911

Nystroem GM, Pedersen AJ, Ottosen LM, Villumsen A (2006) The use of desorbing agents in electrodialytic remediation of harbour sediment. Sci Total Environ 357:25-37

Park JY, Lee YH, Kim SJ, Lee YJ, Yang JW (2007) Surfactantenhanced electrokinetic removal of phenanthrene from kaolinite. J Hazard Mater 140:230-236

Pazos M, Rosales E, Alcantara T, Gomez J, Sanroman MA (2010) Decontamination of soils containing PAHs by electroremediation: a review. J Hazard Mater 177:1-11

Pazos M, Iglesias O, Gomez J, Rosales E, Sanroman MA (2013) Remediation of contaminated marine sediment using electrokinetic-Fenton technology. J Ind Eng Chem 19:932-937

Peng G, Tian G (2010) Using electrode electrolytes to enhance electrokinetic removal of heavy metals from electroplating sludge. Chem Eng J 165:388-394

Reddy KR (2010) Technical challenges to in situ remediation of polluted sites. Geotech Geol Eng 28:211-221

Reddy KR, Ala PR, Sharma S, Kumar SN (2006) Enhanced electrokinetic remediation of contaminated manufactured gas plant soil. Eng Geol 85:132-146

Reddy K, Maturi K, Cameselle C (2009) Sequential electrokinetic remediation of mixed contaminants in low permeability soils. J Environ Eng 135:989-998

Reddy KR, Cameselle C, Ala P (2010) Integrated electrokinetic-soil flushing to remove mixed organic and metal contaminants. J Applied Electrochem 40:1269-1279

Ryu BG, Park GY, Yang JW, Baek K (2011) Electrolyte conditioning for electrokinetic remediation of $\mathrm{As}, \mathrm{Cu}$, and $\mathrm{Pb}$-contaminated soil. Sep Purif Technol 79:170-176

Suer P, Gitye K, Allard B (2003) Speciation and transport of heavy metals and macroelements during electroremediation. Environ Sci Technol 37:177-181

Vyrkutyte J, Sillanpaa M, Latostenmaa P (2002) Electrokinetic soil remediation - critical overview. Sci Total Environ 289:97-121

Wang JY, Huang XJ, Kao JCM, Stabnikova O (2007) Simultaneous removal of organic contaminants and heavy metals from kaolin using an upward electrokinetic soil remediation process. J Hazard Mater 144:292-299

Yang Y, Ratté D, Smets B, Pignatello J, Grasso D (2001) Mobilization of soil organic matter by complexing agents and implications for polycyclic aromatic hydrocarbon desorption. Chemosphere 43:1013-1021

Yang JW, Lee YJ, Park JY, Kim SJ, Lee JY (2005) Application of APG and Calfax 16L-35 on surfactant-enhanced electrokinetic removal of phenanthrene from kaolinite. Eng Geol 77:243-251

Yuan C, Chiang TS (2008) Enhancement of electrokinetic remediation of arsenic spiked soil by chemical reagents. J Hazard Mater 152:309-315

Yuan C, Weng CH (2006) Electrokinetic enhancement removal of heavy metals from industrial wastewater sludge. Chemosphere 65:88-96

Zhang SY, Wang QF, Xie SG (2012) Molecular characterization of phenanthrene-degrading methanogenic communities in leachatecontaminated aquifer sediment. Int $\mathrm{J}$ Environ Sci Technol 9:705-712

Zhu L, Fen S (2003) Synergistic solubilization of polycyclic aromatic hydrocarbons by mixed anionic-nonionic surfactants. Chemosphere 53:459-467 